\title{
RESEARCH ON REMOTE SENSING GEOLOGICAL INFORMATION EXTRACTION BASED ON OBJECT ORIENTED CLASSIFICATION
}

\author{
GAO.Hui ${ }^{1}$ \\ ${ }^{1}$ Chengdu Center, China Geological Survey, Chengdu, China, @ chengdu.cgs.gov.cn
}

\begin{abstract}
KEY WORDS : Remote sensing geological information, Object oriented classification, Northern Tibet, High-resolution remote sensing data, Automatic extraction
\end{abstract}

\begin{abstract}
:
The northern Tibet belongs to the Sub cold arid climate zone in the plateau. It is rarely visited by people. The geological w orking conditions are very poor. However, the stratum exposures are good and human interference is very small. Therefore, the research on the automatic classification and extraction of remote sensing geological information has typical significance and good application prospect. Based on the object-oriented classification in Northern Tibet, using the Worldview2 high-resolution remote sensing data, combined with the tectonic information and image enhancement, the lithological spectral features, shape features, spatial locations and topological relations of various geological information are excavated. By setting the threshold, based on the hierarchical classification, eight kinds of geological information were classified and extracted. Compared with the existing geological maps, the accuracy analy sis shows that the overall accuracy reached $87.8561 \%$, indicating that the classification-oriented method is effective and feasible for this study area and provides a new idea for the automatic extraction of remote sensing geological information.
\end{abstract}

\section{INTRODUCTION}

The extraction of remote sensing geological information is an important part of remote sensing application. Due to the complexity of geological conditions and the interference of human engineering activities, visual interpretation has always been the main method of remote sensing. However, as the classification technology advances, the object-oriented classification method provides the possibility for the automation of remote sensing geological information extraction. The traditional pixel classification ignores the rich spatial semantics and texture structure information in high and mid-high spatial resolution images. However, the object-oriented classification method realizes simulation and description of geographic entity features by image object implementation, and establishes quantized expression model of geosciences characteristics, such as pixel spectrum, texture, shape, and the spatial relationship of features, provide the characteristic basis for classification. (Chen Qihao,2007); and object-oriented classification can avoid the "salt and pepper" phenomenon caused by the conventional pixel-based classification method, and achieve higher precision(Chen Jie,2010b).

The object-oriented classification method involves many remote sensing applications. For example, Kong Bo uses multi-source data to achieve good results in object-oriented classification of international river land cover (Kong Bo et al.,2015a); Bhaskaran using IKONOS image for object oriented multi scale urban segmentation(Bhaskaran S et al.,2010a); Dai Jing-jing using object-oriented classification of IKONOS image to extract rare earth mining area of Xunwu in Jiangxi province. (Dai Jing- jing et al.,2017a) ; Cui Yuhuan using the object-oriented classification method based on multi-scale segmentation has made very good results for the winter wheat plantation information extraction(Cui Yuhuan et al.,2017a). Tibet is a region at high altitude, where people are scarcely present and conditions of geological survey are poor. However, strata in arid regions of northern Tibet are exposed with fewer human interventions and high levels interpretation of remote sensing. Therefore, remote sensing is particularly important for such regions. Using Worldview2 high-resolution 8-band bundled remote sensing images to excavate the relevant feature information in the study area located in the northern Tibet Plateau, the object-oriented classification and extraction of remote sensing geological information is carried out by using hierarchical classification and multiple segmentation. It provides a new idea for the automatic extraction of remote sensing geological information.

\section{GENERAL SITUATIONS OF S TUDY REGION}

The study area is located in the northern Tibet Plateau and belongs to the plateau region of sub-cold and arid climate. Thin air, cold and dry climate, sunshine time specialty, strong radiation, regardless of seasons, long freezing period, frost-free period is short. The periphery of the study area belongs to the inland lake basin area of the plateau, with relatively large height difference, generally up to $800 \mathrm{~m}$. The rivers in the area are well developed, with a northwest and south-east converging forked distribution. Some of the small rivers are seasonal rivers, and saline-alkali land and Gobi desert are well-developed. Vegetation is rarely covered and the rocks are exposed. Fracture structure 
runs through the whole research area. The Permian, Jurassic, Neogene and Quaternary systems are mainly exposed in the study area. The Permian is built of dolomite, the Jurassic is made of sand slate, the Neogene is made of conglomerate mudstone, and the Quaternary is built of alluvium and diluvium. Magmatic rocks are mainly quartz diorite and granodiorite porphyry veins.

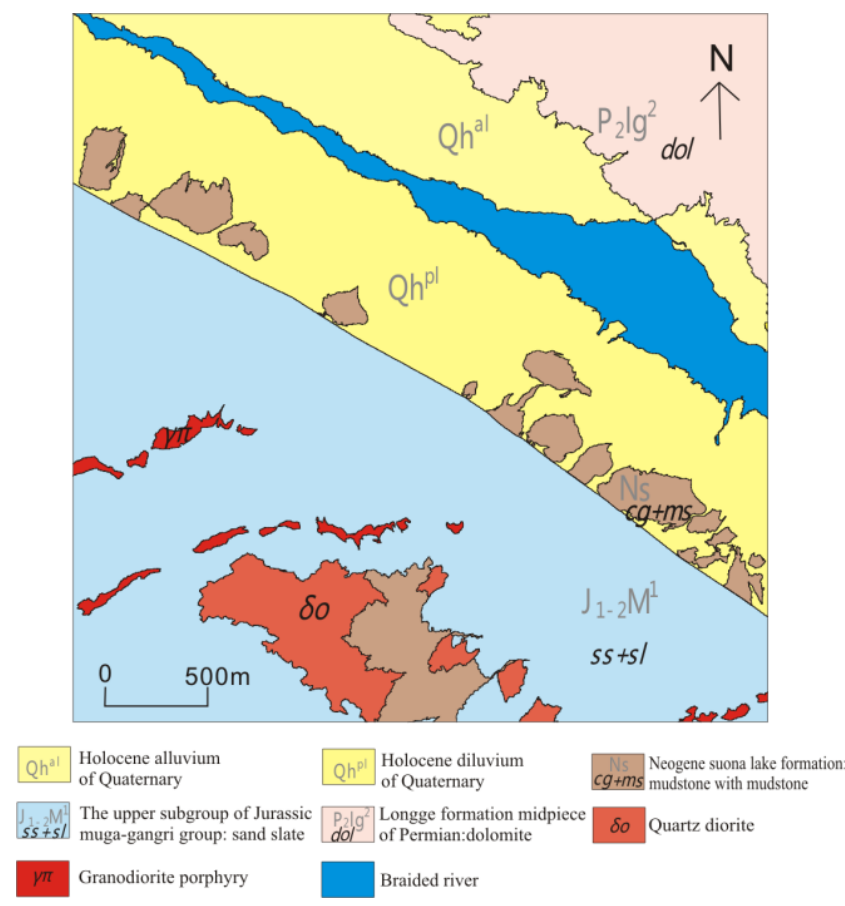

Figure 1 Simplified geological map of research area

\section{DATA SOURCE AND PREPROCESSING}

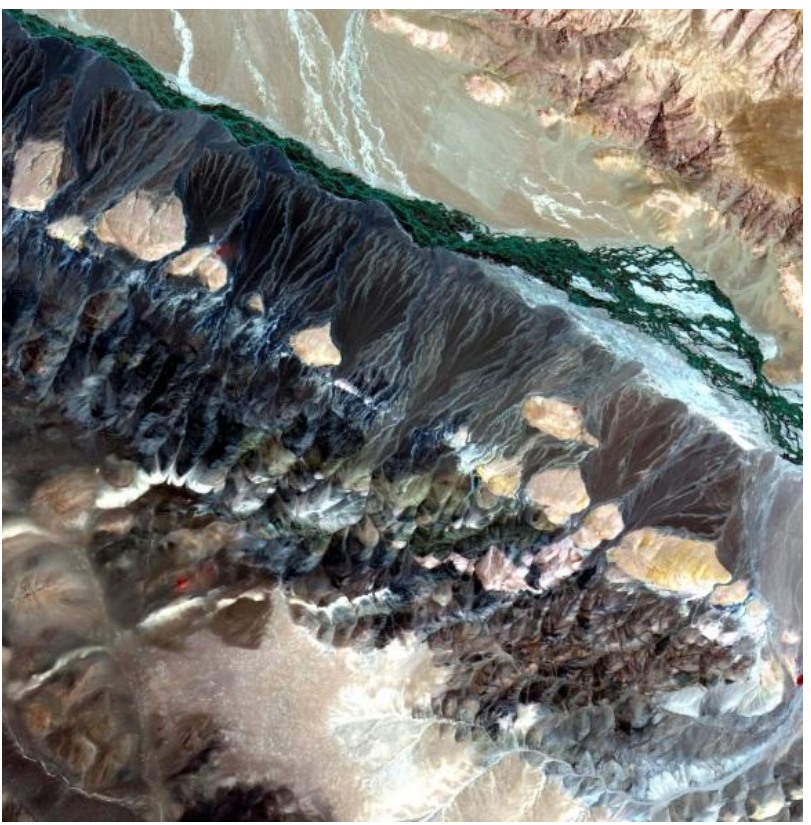

Figure 2843 band combination

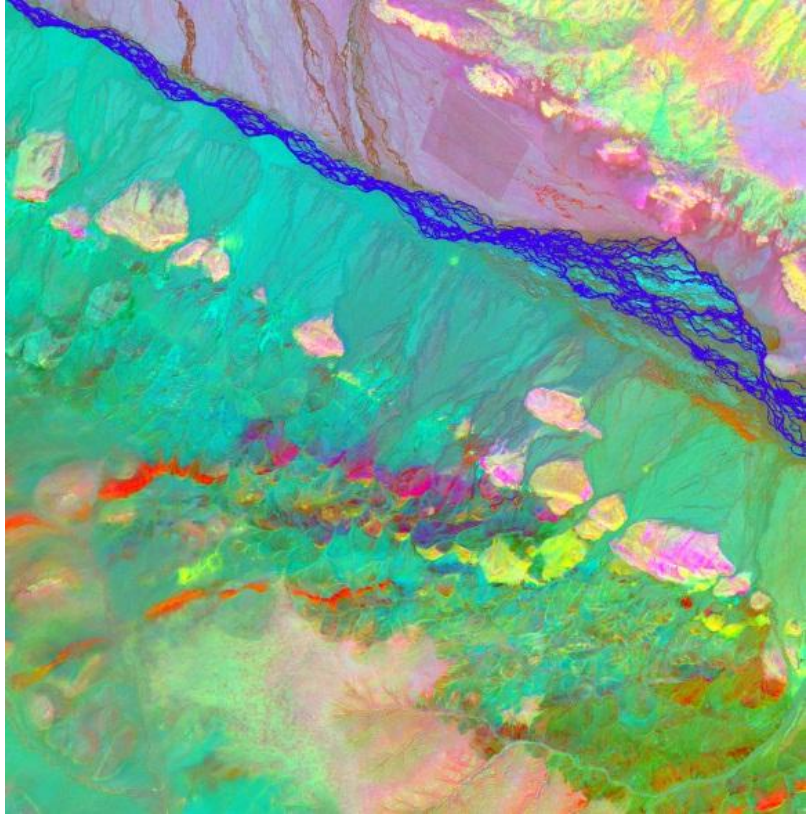

Figure 3 mnf531 band combination

Worldview2 high-resolution remote sensing images as the main data source, including 8 bands, with good image quality and cloudless snow. After completing the atmospheric correction on Worldview 2, the best data band combination is optimized to determine the type of band combination used primarily for threshold determination in the subsequent classification. Following the principle that the sum of the correlation coefficients of the three bands reaches the minimum, according to the spectral characteristics of lithology and tectonics, as well as the interpretation of the visual experience, combined with the correlation coefficient between the band results, the final determination of 843 as the best band combination. Through the minimum noise fraction rotation of 8 bands, the information is concentrated in a few bands. According to the result of transformation, the optimal band combination is supplemented. Due to the limited space, this part will not be described in detail.

\section{GEOLOGICAL INFORMATION EXTRACTION}

\subsection{Extraction Ideas and Processes}

First of all, the object-oriented classification method is to segment the remote sensing image to obtain homogenous objects, and then detect and extract various features of the target object according to the remote sensing classification or the specific requirements of the target object. The fault vector file is added as a dividing line in the segmentation. The result of segmentation is controlled by three parameters: scale parameter, shape and compactness. Different geological information has different requirements for these three scales in the segmentation. Therefore, the study area is divided into primary segmentation and re-segmentation according to the needs of different extraction types. It effectively solves the problem that a single segmentation parameter may be too thin or too thick due to different sizes of different geological information. 
The geological information extraction process in the study area is based on the hierarchical classification as the main idea, the extraction process is divided into three levels, the first layer is divided into braided river and unclassified, because of the braid river has the most prominent spectral features in the eight kinds of classes and. According to the spatial distribution characteristics of lithology, the two layers are divided into three categories. According to the analysis, the lithology in the study area is consistent with the fault direction, and is roughly a nearly parallel distribution in the NW direction. In the last layer, the sub-categories, according to the classification of the classification before the standard-scale segmentation, reduce the fragmentation of the patch, while retaining the details of the initial segmentation. The geological information extraction process is shown in the figure 4 . The discrimination conditions in the flowchart will be detailed later.

\subsection{Extraction Rules Established}

4.2.1 Extraction of Braided River: In this paper, we use the perimeter ratio between the public side and the unclassified patches of riverbank and water body, and set the threshold of the spectral characteristics. In the following classification, the misclassified patches in other categories are further analyzed for their spectral characteristics, and betrayed by the distance of braided river.

4.2.2 Extraction of the Large Class of Dolomite: The large class of dolomite includes dolomite and alluvium. From the spatial relationship, it can be seen that the large type of dolomite are mainly located on the north side of the study area, and the patches with the ordinate values beyond 6000 are initially classified as dolomite. Because the suitable segmentation scale of dolomite and alluvial are different from that of braided river and the scale is relatively large, the resegmentation of new scale is carried out before the rules are further established. Alluvium spectra were used for threshold setting, including standard deviation, mean and HSI (HueSaturation-Intensity)-transformed saturation, and the dolomite misclassified in the alluvium was corrected using the enclosed spatial relationship, and vice versa, alluvium also use the enclosed spatial relationship to be amended.

4.2.3 Extraction of the Large Class of Diluvium: The Large class of diluvium consists of conglomerate with mudstone and diluvium. Spatial relationships are used to classify patches other than braided rivers with y-coordinates greater than 4,000 into the large class of diluvium, of which conglomerate with mudstone mainly uses spectra and wherein the spatial positional relationship of the spectral characteristics include standard deviation, mean of three bands and the HSI and saturation conversion. Conglomerate with mudstone on one side of the fault, and they are neighbour relationship. After extraction of conglomerate with mudstone, the diluvium were removed again by spectral characteristics in conglomerate with mudstone.
4.2.4 Extraction of the Large Class of Sand slate: Sand slate categories include conglomerate mudstone, granodiorite porphyry, quartz diorite and sand slate. The part of the conglomerate with mudstone in the large class of sand slate was extracted by sum of the mean, and then merged with the conglomerate mudstone extracted from the macrophyte categories. The granodiorite porphyry veins are extracted by the spectral features, including the sum of the mean values of the three bands after MNF (Minimum Noise Fraction Rotation), the saturation and the band ratio after HSI. Quartz diorite is extracted by using its spectral features, including the sum of the mean, the saturation, and the standard deviation after HSI. Sand slate is amended by spectral characteristics in other categories of patches.

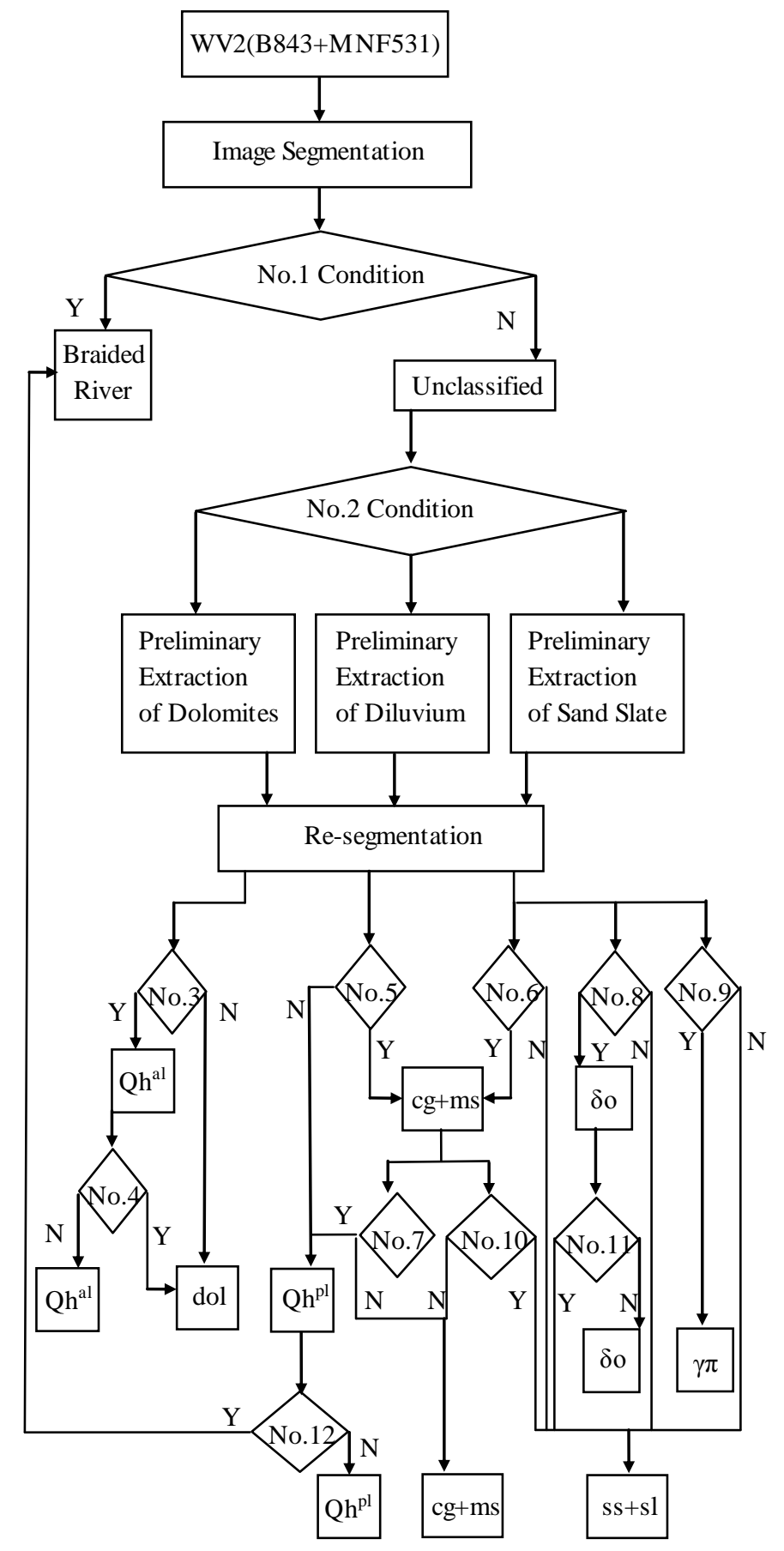


Figure 4. Geological information extraction flow chart

\begin{tabular}{|c|c|}
\hline Class & $\begin{array}{l}\text { Classification threshold or spatial } \\
\text { relationship } \\
\end{array}$ \\
\hline Braided River & $\begin{array}{l}\text { The ratio between the } 4 \text { band mean of the } \\
\text { WV } 2 \text { and the sum of the } 843 \text { band mean is } \\
\text { greater than } 0.3 \text { (No. } 1 \text { condition) } \\
\text { Unclassified within the braided river is } \\
\text { defined as braided river. ( No.1 } \\
\text { condition) } \\
\text { The ratio of the common side lengths of } \\
\text { the unclassified and braided river patches } \\
\text { to perimeter of the unclassified patches is } \\
\text { greater than } 0.3 \text { and the sum of the mean } \\
\text { of the } 843 \text { band of WV2 is less than } 158 . \\
\text { (No. } 1 \text { condition) }\end{array}$ \\
\hline $\begin{array}{l}\text { The Large Class } \\
\text { of Dolomite }\end{array}$ & Y coordinate $>6000$ (No.2 condition $)$ \\
\hline $\begin{array}{l}\text { The Large Class } \\
\text { of Diluvium }\end{array}$ & Y coordinate $>4000$ ( No.2 condition $)$ \\
\hline $\begin{array}{l}\text { The Large Class } \\
\text { of Sand slate }\end{array}$ & Y coordinate $<2000 （$ No. 2 condition $)$ \\
\hline Alluvium & $\begin{array}{l}\text { The standard deviation of WV2 band } 8 \text { in } \\
\text { dolomite is less than } 3 \text {, and the patches of } \\
\text { WV2 whose } 843 \text { band mean sum is greater } \\
\text { than } 180 \text { is classified as alluvium. (No.3 } \\
\text { Condition) } \\
\text { The dolomites contained in alluvium are } \\
\text { classified as alluvium. (No. } 3 \text { condition) } \\
\text { HIS transformation of dolomite after } \\
\text { patches consolidation, the patches } \\
\text { belonging to the } 843 \text { band of WV2 } \\
\text { saturation value greater than } 0.1 \text { were } \\
\text { classified as alluvium. (No. } 3 \text { condition) }\end{array}$ \\
\hline Dolomites & $\begin{array}{l}\text { Alluvium contained in dolomites is } \\
\text { classified as alluvium. (No.4 condition) }\end{array}$ \\
\hline $\begin{array}{l}\text { Conglomerate } \\
\text { with Mudstone }\end{array}$ & $\begin{array}{l}\text { The sum of the } 843 \text { bands of WV2 in the } \\
\text { diluvium is greater than } 185 \text { and is } \\
\text { classified as conglomerate with mudstone. } \\
\text { (No.5 condition) } \\
\text { Adjacent to the fault in the sand slate, the } \\
\text { sum of mean about the } 843 \text { bands of WV2 } \\
\text { is greater than 180, and the saturation less } \\
\text { than } 0.138 \text { after HIS transform in the } 843 \\
\text { bands is classified as conglomerate with } \\
\text { mudstone. (No.6 condition) } \\
\text { The diluvium encircled by the } \\
\text { conglomerate with mudstone into the } \\
\text { conglomerate with mudstone ( No.5 } \\
\text { condition) } \\
\text { The sum of the mean value of } 843 \text { band of } \\
\text { WV2 in the sand slate is more than } 222 \\
\text { into the conglomerate with mudstone. } \\
\text { (No.6 Condition) }\end{array}$ \\
\hline Diluvium & $\begin{array}{l}\text { The ratio of the mean value of the band } 8 \\
\text { of WV2 to the sum of the mean value of } \\
\text { the } 843 \text { band in the conglomerate }\end{array}$ \\
\hline
\end{tabular}

\begin{tabular}{|c|c|}
\hline & $\begin{array}{l}\text { mudstone is less than } 0.31 \text { into the } \\
\text { diluvium. (No. } 7 \text { condition) }\end{array}$ \\
\hline $\begin{array}{l}\text { Granodiorite } \\
\text { porphyry is }\end{array}$ & $\begin{array}{l}\text { After the MNF transformation ,the sum of } \\
\text { the band } 1,3,5 \text { mean is greater than } 6 \text { and } \\
\text { the brightness value of the HSI transform } \\
\text { is greater than } 0.05 \text {, the ratio of the band } 1 \\
\text { to the band } 135 \text { mean value is greater than } \\
1.5 \text {. (No.8 condition) }\end{array}$ \\
\hline Quartz diorite & $\begin{array}{l}\text { In the sand slate, the sum of the mean is } \\
\text { greater than } 182 \text { and the standard deviation } \\
\text { of the band less than } 0.1 \text { in the WV } 2 \text { band } \\
843 \text { after HSI transform. The standard } \\
\text { deviation of } 8 \text { bands is less than } 3 \text {, and } \\
\text { patches larger than } 1.7 \text { are classified into } \\
\text { quartz diorite. (No.9 condition) }\end{array}$ \\
\hline Sand slate & $\begin{array}{l}\text { When the sum of the mean of the } 843 \text { band } \\
\text { of WV } 2 \text { in conglomerate mudstone is less } \\
\text { than } 200 \text {, the patches are classified as the } \\
\text { sand slate. (No. } 10 \text { condition) } \\
\text { When the sum of the mean values of bands } \\
135 \text { after MNF transformation in } \\
\text { conglomerate with mudstone is less than } \\
31 \text {, the patches are classified as the sand } \\
\text { slate. (No. } 10 \text { condition) } \\
\text { When the sum of the mean of the } 843 \text { band } \\
\text { of WV2 in granodiorite porphyry is less } \\
\text { than } 185 \text {, the patches are classified as the } \\
\text { sand slate. (No. } 11 \text { condition) }\end{array}$ \\
\hline
\end{tabular}

Table 1. Geological information extraction rules

\section{EXTRACTION RESULTS AND ACCURACY EVALUATION}

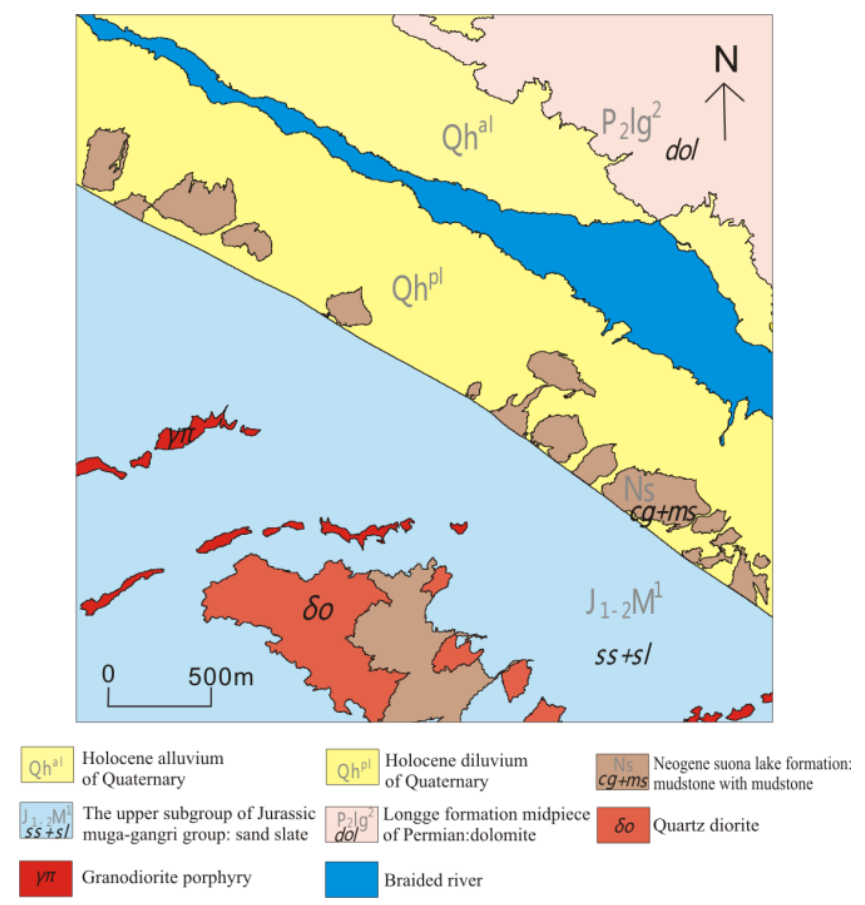

Figure 5 Automatic extraction results 
Accuracy analy sis is based on the actual geological map as a real classification extraction map for the accuracy of geological information extracted automatically. The comparison result of the extraction results shows that the geological information extraction position is in good agreement with the geological map, with an overall accuracy of $87.8561 \%$ and a kappa coefficient is 0.8434. The extraction accuracy quaternary products such as alluvium, braided rivers, diluvium, is high, and as well as the dolomite. The lower the classification accuracy is mainly granodiorite porphyry and quartz diorite, in which the granodiorite porphyry is veins, the discontinuity of appearance on the surface is incomplete. There are two possibilities of veins in the southeast side of the map extraction error: one is due to the limited precision of spectral remote sensing data sources which cause objects with the same spectrum, and the other is the omission of the geological survey due to the problem of the mapping accuracy.

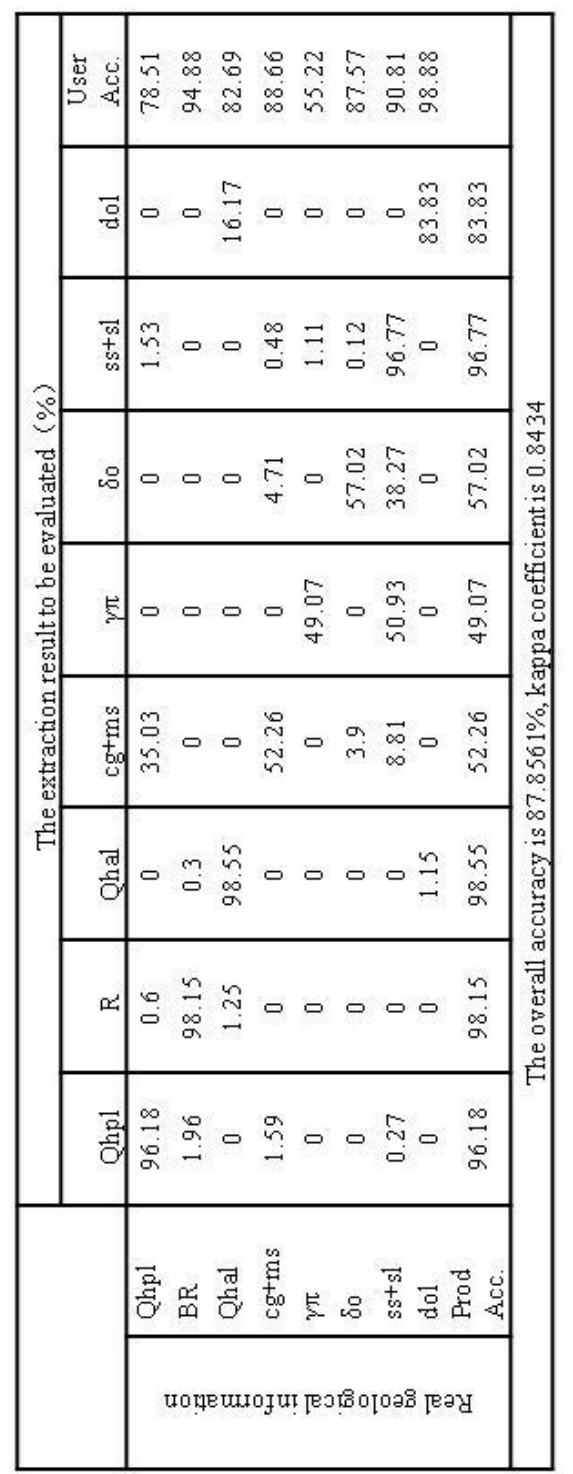

Table2 Error matrix analy sis

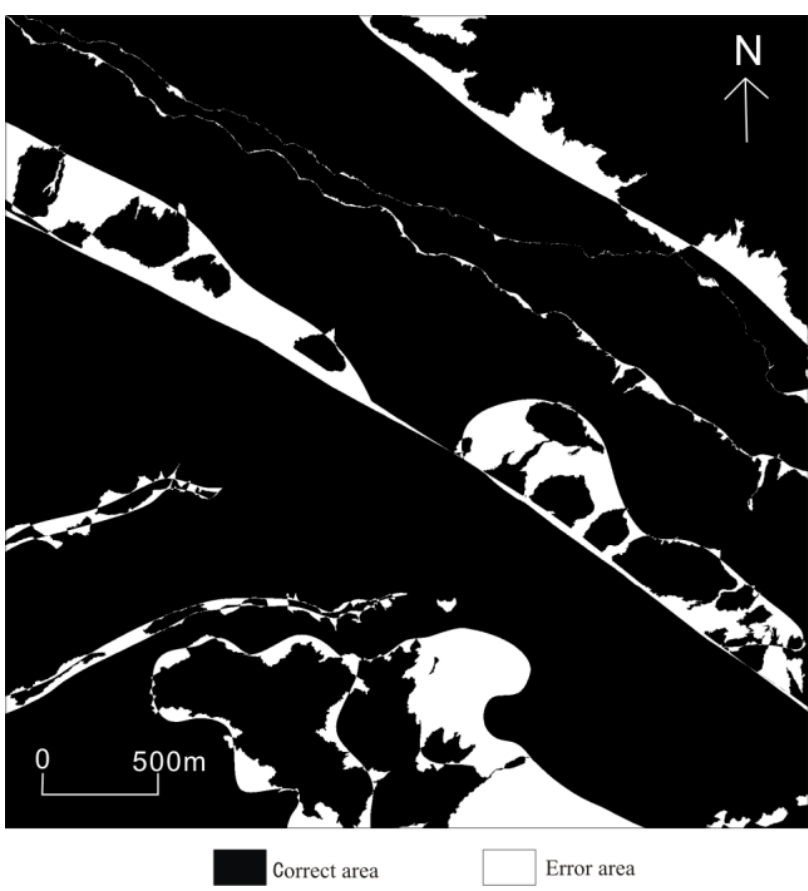

Figure 6 Comparison of the results of extraction

\section{RESULTS AND DISCUSSION}

Using Worldview2 high-resolution 8-band bundled remote sensing image as data source, combined with structural information and a variety of image enhancement methods, lithological spectral features, shape features, spatial locations and topological relations of different geological information are extracted. Using object-oriented classification method to set reasonable thresholds, the eight types of geological information in the study area were extracted. The classification process was classified as the dominant ideology, and the error rate of classification results was effectively controlled. Through the resegmentation between different levels, the method effectively solves the problem of extracting geological information of different scales, obtains the ideal extraction boundary and obtains better classification results. The overall accuracy of the classification extraction reaches $87.8561 \%$.

Geological information as a complex underground information, the appearance of the surface and the degree of weathering determines the extent of interpretation of remote sensing, the interpretability of the data source has an essential impact on the extraction results, and therefore the application of remote sensing automatic interpretation is not extensive, but for such areas as drought and stratigraphic well-exposed areas in Tibet can make useful attempts. Object-oriented classification extraction method can comprehensively mine more information and provide more possibilities for extracting geological information. However, it is found that there are still more manual intervention and arbitrariness in the setting of thresholds and parameters, and the experience of experts has a great relationship, therefore, the next step will be more scientific on how to set parameters for further research. 


\section{ACKNOWLEDGEMENTS}

Acknowledgements of support for the southwest sanjiang nonferrous metal resource base investigation project (number: DD20160016), and 21st century space technology application co., LTD.

\section{REFERENCES}

Chen Yunhao.,Feng Tong., Shi Peijun.,et al.,2006a.Classification of Remote Sensing Image Based on Object Oriented and Class Rules. Geometrics and Information Science of Wuhan University, 31(4):316-320

Chen Qihao.,2007. Research and Realization of Multi-Sources Remote Sensing Data on Object Oriented. Wuhan: China University of Geosciences.

Blaschk E T.,Lang S.,Lorup E.,et al.,2000b.Object-oriented Image Processing in an Integrated GIS/Remote Sensing Environment and Perspectives for Environmental Applications. Environmental Information for Panning, Politics and the Public Metropolis Verlag, Marburg.

Mauro C., Eufemia T.,2001a.Accuracy Assessment of Penfield Classification Integrating very Fine Spatial Resolution Satellite Imagery with Topographic Dat.Journal of Geospatial Engineering, 3(2):127-134.

Benz U C.,Hofmann P.,Illhauck W G.,et al.,2004a.Multiresolution,Object-oriented Fuzzy Analysis Is of Remote Sensing Data for GIS Ready Information.ISPRS Journal of Photogrammetry and Remote Sensing,,58:239-258.

Chen Jie., 2010b. Study on Object-based Classification of Highresolution Remote Sensing Imagery. Hunan: Central South University.

Mo Lijiang.,Cao Yu.,Hu Yuan-man., LIU Miao., XIA Dong.,2012a.Object-oriented Classification for Satellite Remote Sensing of Wetlands: A Case Study in Southern Hangzhou Bay Area. Wetland Science, 10(2): 206-213.

Yu Xianchuan.,An Weijie.,He Hui.,2012a.A method of autoclassification based on object oriented unsupervised classification. Progress in Geophysics, 27(2): 744-749.

Kong Bo.,Deng Wei.,et al.,2015a. Object-oriented Landcover Classification of Multi-source Remote Sensing Data in International Trans-boundary River n. Geomatics and Information Science of Wuhan University,40(7):943-949.

Bhaskaran S,Paramananda S, 2010a.Ramnaray an M.Perpixel and Object-Oriented Classification Methods for Mapping Urban Features Using IKONOS Satellite Data.Applied Geography, 30:650-665.

Dai Jingjing.,Wu Yanan.,et al.,2017a. Object-oriented Classification for the Extraction of Remote Sensing Information in Rare Earth Mining Areas. Acta Geoscientica Sinica.Vol.3x No.x: 1-8.

Cui Yuhuan.,Wang Jie.,Yao Mengyuan.,2017a. Remote sensing monitoring of winter wheat planting area based on objectoriented method - a case study of Lin huan mining area in Huaibei City. 44(6): 1-4. 